\title{
Does kidney function matter in pulmonary thromboembolism management?
}

\author{
Magdalena Pływaczewska, Piotr Pruszczyk, Maciej Kostrubiec
}

Department of Internal Medicine and Cardiology, Medical University of Warsaw, Poland

\begin{abstract}
Cardiovascular circulation and kidney function are closely interrelated. The impairment of renal function is a well-known hazard of increased mortality and morbidity of patients with heart failure or coronary artery disease. Acute pulmonary embolism (APE) impacts pulmonary and systemic circulation, and can severely impair functions of other organs, including kidneys, as a result of hypoxemia and increased venous pressure.

Previous studies indicate that renal dysfunction predicts short-and long-term outcomes and can improve the risk assessment in APE. However, renal function should also be cautiously considered during the diagnostic workup because the contrast-induced nephropathy after computed tomography pulmonary angiography is noticed more frequently in APE. Chronic thromboembolic pulmonary hypertension $(C T E P H)$ is a rare but imminent complication of APE. This condition promotes renal impairment by increasing venous pressure and decreasing glomerular filtration. The renal function improvement and serum creatinine concentration reduction were noted in CTEPH subgroup with glomerular filtration rate $\leq 60 \mathrm{~mL} / \mathrm{min} / 1.73 \mathrm{~m}^{2}$ after successful treatment.

In this review, we present the essential research results on the kidney function in thromboembolism disease. (Cardiol J 2022; 29, 5: 858-865)
\end{abstract}

Key words: renal dysfunction, contrast-induced nephropathy, pulmonary embolism, chronic thromboembolic pulmonary hypertension, prognosis, mortality

\section{Introduction}

Cardiovascular diseases are the most frequent causes of morbidity and mortality in the general population, and impaired renal function is a broadly known risk factor increasing mortality [1]. The association between kidney function and diseases of heart and vessels seems to be obvious. Approximately $4.5 \%$ of the general population has a glomerular filtration rate (GFR) $<60 \mathrm{~mL} / \mathrm{min}$ [2], which puts them at risk.

To assess renal function, serum plasma creatinine and GFR are the most widely used. However, the direct measurement of GFR is usually avoided, and its estimations based on the modification of Diet in Renal Disease (MDRD) [3] and the Cockcroft-Gault (C-G) formula [4] are convenient and accurate substitutes.
Acute pulmonary embolism (APE) does not only have an impact on pulmonary but also systemic circulation and can impair functions of other organs causing hypoxemia and increased venous pressure. It should be underlined that kidneys are susceptible to hypoxemia [5]. The previous studies indicate that renal dysfunction predicts short- and long-term outcomes and can improve the risk assessment in APE [6, 7]. However, kidney function and its assessment are essential in various thromboembolic disease.

\section{At diagnosis}

In patients with high clinical probability and abnormal D-dimer levels, computed tomography pulmonary angiography (CTPA) is performed not only to confirm the diagnosis of APE but also to ob-

Address for correspondence: Magdalena Pływaczewska, MD, Department of Internal Medicine and Cardiology, Medical University of Warsaw, ul. Lindleya 4, 02-005 Warszawa, Poland, tel: +48 517930273, e-mail: ma.plywaczewska@gmail.com 
tain information about possible right ventricle (RV) dysfunction [8]. Nevertheless, CTPA can trigger contrast-induced acute kidney injury (CI-AKI) [9], which is usually defined as an increase of creatinine level $\geq 0.5 \mathrm{mg} / \mathrm{dL}$ or $>25 \%$ from baseline within 48 hours of contrast usage [10]. Some studies have suggested that APE patients are more vulnerable to, and more frequently experience, CI-AKI. Firstly APE is a condition leading to impairment of renal function. As a consequence of thrombi closure and vasoconstriction of the pulmonary arteries, pulmonary resistance rises, and subsequently the pressure in the RV also increases. Hemodynamic destabilization of the RV effects a reduction in left ventricular load and, consequently, a reduction in stroke volume and systemic hypotension [11]. Because the RV is not adapted to sudden pressure overloads, its failure occurs, which results in congestion in the peripheral circulation. The increase of a central venous pressure leads to a stagnation of blood in central veins and subsequent passive hyperemia of liver and kidneys [12]. Elevated central venous pressure, hypoxemia and decreased cardiac output results in organ hypoperfusion [13] and can be a factor in renal dysfunction [14]. Coexisting hypoxemia is a result of pulmonary circulatory failure and leads to ischemic damage [15]. Kidneys are among the most sensitive organs to hypoxemia [5]. Increased venous pressure causes a reduction of trans-glomerular pressure gradients and impairs kidney perfusion. This mechanism also activates the renin-angiotensin-aldosterone system (RAAS) and the sympathetic nervous system leading to oxygenic stress and further renal function impairment.

Moreover, as a consequence of respiratory failure, a lower level of $\mathrm{pH}$ and bicarbonate is observed in arterial blood. This state promotes the production of reactive oxygen species, which aggravate already present ischemic damage. One of the suspected mechanisms of CI-AKI is also an ischemic injury of the renal medulla and production of reactive oxygen species, which damage tubules and endothelium [16]. We can conclude that all of APE's pathophysiological consequences promote kidney dysfunction and the occurrence of CI-AKI.

Kooiman et al. [17], in a group of 237 patients with suspicion of pulmonary embolism, studied the frequency and risk factors of contrast-induced nephropathy (CIN) after CTPA. The prevalence of CIN was $8.9 \%$. Independent predictors of impaired renal function after contrast administration were age over 75 years, diabetes mellitus, non-steroidal anti-inflammatory drug use, and multiple myeloma. Doganay et al. [18], in a retrospective study of 122 patients with confirmed APE, showed that the incidence of CI-AKI is more frequent in APE than in other conditions examined with contrast-enhanced computed tomography, $13 \%$ vs. $3-4 \%$, respectively. The logistic regression analysis confirmed lower $\mathrm{pH}$ in arterial blood gas and older age as the risk factors of CI-AKI. Other remarkable hazards were chronic heart failure, higher pressure in pulmonary artery estimated in transthoracic echocardiography, administration of angiotensin converting enzyme inhibitors (ACE-I) or angiotensin receptor blocker (ARB), and low $\mathrm{HCO}_{3}{ }^{-}$. Some of these factors, like age, chronic heart failure, and treatment with ACE-I or ARB, can be found in the risk score scale created by Mehran et al. [19] for patients after a coronary intervention. However, additional hazards are more frequent in patients with APE, especially high and moderate-high risk class according to the European Society of Cardiology (ESC) [8]. Summarizing, there is a remarkable overlap of the risk factors between the CIN risk score [19] and the APE risk score [20]. Consequently, Ho and Harahsheh [21] created the study comparing CIN risk score and pulmonary embolism severity index (PESI) in the prediction of renal insufficiency in critically ill patients suspected on APE. They included 137 intensive care unit (ICU) patients without end-stage renal failure. The study revealed that CIN risk score was significantly better than PESI in the prediction of CIN leading to dialysis (area under curve [AUC] $0.864,95 \%$ confidence interval [CI] $0.795-0.916$ vs. $0.731,95 \%$ CI $0.649-0.804$; $\mathrm{p}=0.001$, respectively). However, PESI had the advantage of better survival prognosis (AUC 0.794, $95 \%$ CI $0.716-0.858$ vs. $0.625,95 \%$ CI $0.538-0.706$; $\mathrm{p}=0.001$ ). The authors suggested that in critically ill patients with suspicion of APE and high risk of CIN, other diagnostic methods should be considered instead of CTPA. Michell et al. [22] showed that after CTPA the frequency of CIN is higher than after other contrast procedures, at $14 \%$ vs. $10 \%$, respectively.

Additionally, the prevalence of $\mathrm{CIN}$ was related to increased risk of poor outcome, such as severe renal failure and death (16\% of patients with CIN after CTPA). The guidelines of the Contrast Medium Safety Committee 2018 [23] recommend hydration (saline or sodium bicarbonate) to prevent CI-AKI in patients at risk of this complication. In a randomized control trial, Turedi et al. [24] compared the prophylaxis of CIN after CTPA with $\mathrm{N}$-acetylcysteine, sodium bicarbonate and saline. In the group of 231 patients, $15.2 \%(32 / 231)$ had CIN, but none of the prophylaxes was more effective. The multivariate logistic regression analysis 
indicated that only basal GFR and the presence of hypotension were independent predictors of CIN development. Kooiman et al. [25] compared a lack of hydration with hydration of $250 \mathrm{~mL} 1.4 \%$ sodium bicarbonate in the prophylaxis of CI-AKI after CTPA in 138 patients with chronic kidney disease (CKD) and suspicion of APE. They did not observe differences in the frequency of CI-AKI between groups, and suggested that not using pre-hydration would avoid a delay in performing CTPA and proper diagnosis. Another interesting study is the recent Kompas Randomized Clinical Trial [26]. In a group of 523 patients with stage 3 of CKD, who underwent contrast-enhanced computed tomography, no hydration was compared with sodium bicarbonate administration. The CI-AKI occurred in 11 (2.1\%) patients. In the no pre-hydration group it was 7 of $262(2.7 \%)$, and 4 of 261 (1.5\%) in the pre-hydration group and the relative risk was 1.7 (95\% CI 0.5-5.9; $\mathrm{p}=0.36$ ). The authors concluded that withholding hydration is safe and cost-effective.

\section{During hospitalization and after discharge}

The risk stratification of pulmonary embolism patients is crucial in the selection of medical management. As previously mentioned, APE impairs not only pulmonary circulation but also the systemic circulation and function of many organs, including kidneys, the dysfunction of which may negatively influence the outcome.

In the ICOPER study, creatinine $>177 \mu \mathrm{mol} / \mathrm{L}$ predicted 3-month mortality [27]. The authors of the Hestia study indicated that the diagnosis of APE in patients with creatine clearance $<30 \mathrm{~mL} /$ /min $(\mathrm{C}-\mathrm{G})$ should be the premise for in-hospital treatment [28]. The studies conducted in our department revealed that renal dysfunction predicted short and long-term outcome and could be useful in improving the risk assessment in APE [6]. In a group of 2247 APE patients hospitalized in three European centers, GFR $\leq 60 \mathrm{~mL} / \mathrm{min} / 1.73 \mathrm{~m}^{2}$ calculated by MDRD was a risk factor of mortality during 30- and 180-day observation. Moreover, the inclusion of GFR $\leq 60 \mathrm{~mL} / \mathrm{min} / 1.73 \mathrm{~m}^{2}$ enhanced the ESC risk stratification model, with a net reclassification index (NRI) of 0.42. The impaired kidney function, assessed as a drop in eGFR, was also linked with a higher occurrence of bleeding (odds ratio [OR] 0.90 per $10 \mathrm{~mL} / \mathrm{min} / 1.73 \mathrm{~m}^{2}$, 95\% CI 0.85-0.95; $\mathrm{p}=0.0002$ ). The analysis of the same group of patients showed no significant difference in mortality prediction between the two GFR estimation formulas: C-G vs. MDRD. The areas under the receiver operating characteristics curves for both the methods were similar [29].

The comparison of various methods of GFR estimation (C-G vs. CKD-EPI) was recently performed on data from the RIETE registry [30]. Among the 4676 patients with GFR $\leq 30 \mathrm{~mL} / \mathrm{min}$ according to at least one of the formulas, these result was not confirmed in $40.7 \%$ individuals by the other equation. However, patients with a diagnosis of severe renal impairment, regardless of the method used for GFR calculation, had a higher rate of major bleedings during anticoagulation treatment (approximately $10 \%$ vs. $4 \%$ ). In the subgroups with low GFR the all-cause mortality rates were higher than in patients without severe renal failure.

In another single-center study eGFR $\leq 35 \mathrm{~mL} /$ $/ \mathrm{min}$ in normotensive APE patients was associated with higher risk of 30-day mortality and, when combined with the troponin level, also improved risk stratification [7]. Similarly, Altinsoy et al. [31] in a multivariate analysis demonstrated that GFR estimated by CKD-EPI or MDRD coexisting with an elevated troponin concentration were independent predictors of an adverse outcome in normotensive patients with APE. In this study, the GFR also correlated with $\mathrm{RV}$ dysfunction.

Serum creatine measurement is variable and reflects somewhat the functional changes of glomerular filtration roughly mirroring kidney injury [32]. New markers surpass serum creatinine in assessing renal filtration as well as glomerular or tubulointerstitial damage. Because of the early occurrence of novel renal markers, the diagnosis of kidney dysfunction might be suspected before any change in creatinine concentration. Neutrophil gelatinase-associated lipocalin (NGAL) [33] and cystatin $\mathrm{C}$ are examples of these compounds [34]. A study of APE patients showed that NGAL plasma levels were significantly higher in non-survivors [35]. Furthermore, increased levels of NGAL and cystatin $\mathrm{C}$ in patients with APE were associated with higher 30-day all-cause, pulmonary embolismrelated, and 180-day mortality. The elevation of NGAL in a group with low risk of death due to APE had 100\% negative predictive value for 30-day all-cause death. Plasma concentration of cystatin $\mathrm{C}$ was the most significant predictor of death in multivariable analysis. Even though novel biomarkers seem to be more precise than those based on serum creatinine GFR, they are rarely available and are not commonly used (Table 1 ). 
Table 1. Overview of important studies on renal function impairment in acute pulmonary embolism (APE).

\begin{tabular}{|c|c|c|c|}
\hline $\begin{array}{l}\text { Study or author's } \\
\text { name }\end{array}$ & Year & $\begin{array}{l}\text { Patients } \\
\text { group }\end{array}$ & Main results \\
\hline ICOPER study [27] & 1999 & 2454 & Creatinine $>177 \mu \mathrm{mol} / \mathrm{L}$ predicts 3-month mortality \\
\hline Kostrubiec el al. [7] & 2010 & 220 & $\begin{array}{c}\text { eGFR } \leq 35 \mathrm{~mL} / \mathrm{min} \text { in normotensive APE } \\
\text { patients increases the risk of } 30 \text {-day mortality } \\
\text { eGFR combined with troponin level - improves } \\
\text { the risk stratification }\end{array}$ \\
\hline Kostriubiec et al. [35] & 2012 & 142 & $\begin{array}{l}\text { NGAL plasma level was significantly higher in non-survivors } \\
\text { Increase level of NGAL and cystatin } \mathrm{C}-\text { higher rate of } 30 \text {-day } \\
\text { all-cause and pulmonary embolism-related mortality, } \\
\text { and } 180 \text {-day mortality } \\
\text { Cystatin } \mathrm{C}-\text { most significant predictor of death in } \\
\text { multivariable analysis }\end{array}$ \\
\hline Hestia study [28] & 2013 & 496 & $\begin{array}{c}\text { APE patients with eGFR }<30 \mathrm{~mL} / \mathrm{min}(\mathrm{C}-\mathrm{G}) \text { as an indicator } \\
\text { of in-hospital treatment }\end{array}$ \\
\hline Altınsoy et al. [31] & 2017 & 99 & $\begin{array}{l}\text { GFR (CKD-EPI or MDRD) with elevated troponin is } \\
\text { an independent predictor of adverse outcome } \\
\text { in normotensive APE } \\
\text { GFR correlated with right ventricle dysfunction }\end{array}$ \\
\hline Ho and Harahsheh [21] & 2018 & 137 & $\begin{array}{l}\text { CIN risk score is significantly better than PESI in } \\
\text { the prediction of CIN leading to dialysis } \\
\text { PESI has the advantage of better survival prognosis }\end{array}$ \\
\hline Kostrubiec et al. [6] & 2019 & 2247 & $\begin{array}{c}\text { GFR } \leq 60 \mathrm{~mL} / \mathrm{min} / 1.73 \mathrm{~m}^{2} \text { (MDRD) is a risk factor } \\
\text { of } 30 \text { - and } 180 \text {-day mortality } \\
\text { GFR } \leq 60 \mathrm{~mL} / \mathrm{min} / 1.73 \mathrm{~m}^{2} \text { enhanced the European Society } \\
\text { of Cardiology risk stratification }\end{array}$ \\
\hline $\begin{array}{l}\text { Catella et al [30] } \\
\text { RIETE study } \\
\text { sub-analysis }\end{array}$ & 2019 & 4676 & $\begin{array}{l}\text { Severe renal impairment is associated with higher rate } \\
\text { of major bleedings during anticoagulation } \\
\text { Low GFR subgroups with higher all-cause mortality }\end{array}$ \\
\hline
\end{tabular}

CIN — contrast-induced nephropathy; CKD-EPI — Chronic Kidney Disease Epidemiology Collaboration; eGFR — estimated glomerular filtration rate; MDRD - modification of diet in renal disease; NGAL - urinary neutrophil gelatinase-associated lipocalin; PESI - pulmonary embolism severity index

\section{Long-term follow-up after an APE episode}

Chronic thromboembolic pulmonary hypertension (CTEPH) is one of the subtypes of pulmonary hypertension $(\mathrm{PH})$ [36]. The epidemiology of this disease is barely known. In a meta-analysis of 16 studies on CTEPH, its pooled incidence in unselected patients after APE during 2-3 years of follow-up was $0.56 \%$ [37]. Researchers observed that among survivors, the frequency of CTEPH was $3 \%$. Clinical practice suggests that this morbidity rate may be more accurate. The CTEPH is considered to develop as a consequence of the impaired resolution of pulmonary thrombi, which subsequently become endothelized. This leads to chronic obstruction of the pulmonary arteries, high pulmonary vascular resistance, increased pressure in the pulmonary circulation, and progressive right heart failure [12]. In patients with CTEPH, impairment of kidney function also plays an important role. Chronic elevation of central venous pressure secondary to $\mathrm{RV}$ dysfunction runs to high renal venous pressure [38] and a drop in effective filtration pressure [39]. That process activates neurohormonal ways, including RAAS, and pro-inflammatory pathways, which further decline the filtration fraction [40]. The activation of the RAAS also leads to oxidative kidney injury [41, 42]. Additionally, PH worsens the course of CKD [43]. This is associated with a state of elevated catecholamine levels, activation of RAAS, and progressive RV dysfunction [44, 45]. The above cascade deteriorates $\mathrm{PH}$. Summarizing, the impaired renal function may be a consequence of $\mathrm{PH}$ but also might be a reason for $\mathrm{PH}$ exacerbation [46]. Nevertheless, PH is associated with higher mortality in patients with CKD [47].

Chronic thromboembolic pulmonary hypertension is a complication of pulmonary embolism, with abysmal prognosis if left untreated [48]. The first-choice treatment is the surgical removal of 
Table 2. Overview of important studies on renal function impairment in chronic thromboembolic pulmonary hypertension (CTEPH).

\begin{tabular}{|c|c|c|c|}
\hline Study or author's name & Year & Patient group & Main results \\
\hline $\begin{array}{l}\text { Delcroix et al. (International } \\
\text { Prospective Registry) [51] }\end{array}$ & 2016 & $\begin{array}{l}679 \text { patients } \\
\text { with CTEPH }\end{array}$ & $\begin{array}{l}\text { Dialysis-dependent renal } \\
\text { — risk factors of death }\end{array}$ \\
\hline Darocha et al. [58] & 2019 & $\begin{array}{l}250 \text { BPA in } \\
41 \text { patients }\end{array}$ & $\begin{array}{l}\text { Low rate of } \mathrm{CIN}(0.8 \%) \\
\text { Renal function improvement and creatinine } \\
\text { reduction after BPA treatment }\end{array}$ \\
\hline Kriechbaum et al. [60] & 2019 & $\begin{array}{l}265 \text { BPA in } \\
51 \text { patients }\end{array}$ & $\begin{array}{c}\text { Cl-AKI occurred after } 6(2.3 \%) \text { BPA } \\
\text { Patients with CKD - renal function improved after BPA }\end{array}$ \\
\hline Kimura et al. [61] & 2015 & $\begin{array}{l}46 \text { patients } \\
\text { treated by BPA }\end{array}$ & $\begin{array}{l}\text { Upturn of renal filtration in patients with } \\
\text { initially impaired kidney function }\end{array}$ \\
\hline Isobe et al. [62] & 2019 & 45 patients & $\begin{array}{l}\text { Increased of cardiac index and mixed venous oxygen } \\
\text { saturation with a decrease of mPAP and PVR-predictors } \\
\text { of renal insufficiency improvement after BPA }\end{array}$ \\
\hline
\end{tabular}

BPA — balloon pulmonary angioplasty; CI-AKI — contrast-induced acute kidney injury; CIN — contrast-induced nephropathy; CKD — chronic kidney disease; mPAP — mean pulmonary artery pressure; PVR — pulmonary vascular resistance

chronic thrombi from pulmonary arteries, i.e. endarterectomy (PEA) [49]. PEA is considered to be the optimal option but requires a cardiopulmonary bypass with deep hypothermia and total circulatory arrest [50]. The qualification for the procedure should be made by a highly specialized team. The decision depends on the patient's profile, comorbidities, and thrombi location [36]. The rate of operable vs. non-operable patients fluctuates $40-60 \%$ [51]. Successful treatment improves the prognosis and quality of life, and results in a better renal function [52]. According to the registry of 679 patients with CTEPH for the whole cohort, PEA was the strongest independent predictor of survival (HR 0.37; 95\% CI 0.24-0.58; p < 0.0001) [51]. The analysis of preoperative characteristics of operated patients revealed dialysis-dependent renal failure as one of the risk factors of death (HR 11.52; 95\% CI 1.42-93.48; $\mathrm{p}=0.0221$ ). Other independent risks factors of mortality for both the operated and the not-operated group were age, New York Heart Association class, right atrial pressure, history of cancer, left heart failure, and dialysis-dependent renal failure. However, it should be noted that $12-31 \%$ patients after PEA have persistent or recurrent $\mathrm{PH}[53,54]$. Balloon pulmonary angioplasty (BPA) is a feasible PEA alternative for patients with high perioperative risk, distal location of the lesion, or persistent PH [36, 54]. Subsequent percutaneous dilatation of occlusions and opening of obstructed pulmonary arteries improve the hemodynamic status, reduce symptoms, and lead to the decrease of cardiomarker levels [55]. Appropriate and multiple BPA results in the reduction of the pulmonary vascular resistance (PVR) and mean pulmonary artery pressure (mPAP) [56, 57]. The optimal effect is usually achieved after 3-10 BPA sessions [48]. Every BPA session carries a considerable risk of contrast-induced nephropathy. However, Darocha et al. [58] described only 2 (0.8\%) episodes of CIN following $250 \mathrm{BPA}$ procedures in 41 patients, and no patient needed dialysis. Of interest, the renal function improvement and serum creatinine concentration reduction was noted in the CTEPH subgroup with $\mathrm{GFR} \leq 60 \mathrm{~mL} / \mathrm{min} / 1.73 \mathrm{~m}^{2}(12$ patients, $29 \%)$ after BPA treatment. This was accompanied by a drop in mPAP, PVR, and N-terminal-pro-B-type natriuretic peptide and extension of the distance in the 6 -minute walking test. The investigators noted that a relative increase of GFR, from the initiation of BPA therapy throughout the following 3-6 months after BPA, was correlated with relative changes of cardiac index, right atrial pressure, and mixed venous oxygen saturation. The study indicated that the incidence of CIN after BPA was a rare complication in comparison to percutaneous coronary intervention, despite the higher contrast volume. The rationale could be intravenous administration of contrast and better hemodynamic status of patients during BPA [59]. Higher frequency of CI-AKI was described by Kriechbaum et al. [60] in a group of 51 patients undergoing BPA. The AKI occurred after $6(2.3 \%)$ procedures in $5(9.8 \%)$ various patients following $265 \mathrm{BPA}$ sessions. In all cases, AKI was stage I and no distinctive features for these patients from the rest of the study group were found. Analysis of the subgroup of patients with CKD revealed that renal function improved after BPA, which might be related to the improvement of the systemic circulation. Kimura et al. [61] 
observed an upturn of renal filtration in patients with initially impaired kidney function in a group of 46 patients treated with BPA. Nevertheless, the rise of GFR was not significant for the entire study group. A recent study by Isobe et al. [62] indicated that some hemodynamic parameters, such as an increased cardiac index and mixed venous oxygen saturation with a decrease of MPAP and PVR, were predictors of renal insufficiency improvement in patients undergoing BPA. In conclusion, renal function may be significantly improved after successful sessions of BPA due to a drop in venous pressure, lower venous congestion in kidneys, and higher cardiac output (Table 2).

Chronic thromboembolic pulmonary hypertension is not the only type of $\mathrm{PH}$ affecting renal function. The coexistence of $\mathrm{CKD}$ and $\mathrm{PH}$ is obviously the most common in the most frequent type $2 \mathrm{PH}$, secondary to left heart disease [63]. The presence of $\mathrm{PH}$ in patients with renal insufficiency is associated with high all-cause mortality and frequency of cardiovascular events [64]. $\mathrm{PH}$ is a cause of the rapid progression of CKD [65]. Furthermore, CKD exaggerates PH [66].

Research on $\mathrm{PH}$ is developing quickly, increasing our understanding of its pathophysiology. Subsequent to this evolution, a recent paper by Simonneau [67] suggested a change of $\mathrm{PH}$ definition setting up the threshold of mPAP value at $20 \mathrm{mmHg}$ instead of the previous $24 \mathrm{mmHg}$. According to this novel definition, to diagnose pre-capillary $\mathrm{PH}$ $\mathrm{mPAP}>20 \mathrm{mmHg}$ needs to be accompanied by pulmonary arterial wedge pressure $\leq 15 \mathrm{mmHg}$ and PVR $\geq 3$ Wood's units.

\section{Conclusions}

To conclude, kidney function is crucial for the proper management of pulmonary thromboembolism. Renal insufficiency increases the risk of CIN during the diagnostic process. CIN is observed in approximately $13 \%$ of patients undergoing CTPA due to pulmonary embolism suspicion. Both CKD and acute renal injury at pulmonary embolism diagnosis are markers of worse short- and long-term prognosis. The addition of the criterion: GFR below $60 \mathrm{~mL} / \mathrm{min}$, to sPESI can potentially improve risk stratification in APE. The impaired renal function can improve significantly after successful treatment of CTEPH.

\section{Acknowledgments}

Thanks to the Department of Internal Medicine and Cardiology, Medical University of Warsaw, Poland.

Conflict of interest: None declared

\section{References}

1. McCullough P, Kellum J, Haase M, et al. Pathophysiology of the Cardiorenal Syndromes: Executive Summary from the Eleventh Consensus Conference of the Acute Dialysis Quality Initiative (ADQI). Blood Purification. 2014; 37(2): 2-13, doi: 10.1159/000361059.

2. Damman K, Valente MAE, Voors AA, et al. Renal impairment, worsening renal function, and outcome in patients with heart failure: an updated meta-analysis. Eur Heart J. 2014; 35(7): 455-469, doi: 10.1093/eurheartj/eht386, indexed in Pubmed: 24164864.

3. Levey AS, Coresh J, Greene T, et al. Chronic Kidney Disease Epidemiology Collaboration. Using standardized serum creatinine values in the modification of diet in renal disease study equation for estimating glomerular filtration rate. Ann Intern Med. 2006; 145(4): 247-254, doi: 10.7326/0003-4819-145-4200608150-00004, indexed in Pubmed: 16908915.

4. Cockcroft DW, Gault MH. Prediction of creatinine clearance from serum creatinine. Nephron. 1976; 16(1): 31-41, doi: 10.1159/000180580, indexed in Pubmed: 1244564.

5. Fu Q, Colgan SP, Shelley CS. Hypoxia: the force that drives chronic kidney disease. Clin Med Res. 2016; 14(1): 15-39, doi: 10.3121/cmr.2015.1282, indexed in Pubmed: 26847481.

6. Kostrubiec M, Pływaczewska M, Jiménez D, et al. The prognostic value of renal function in acute pulmonary embolism-a multicentre cohort study. Thromb Haemost. 2019; 119(1): 140-148, doi: 10.1055/s-0038-1676522, indexed in Pubmed: 30597508.

7. Kostrubiec M, Łabyk A, Pedowska-Włoszek J, et al. Assessment of renal dysfunction improves troponin-based short-term prognosis in patients with acute symptomatic pulmonary embolism. J Thromb Haemost. 2010; 8(4): 651-658, doi: 10.1111/j.15387836.2010.03762.x, indexed in Pubmed: 20088923.

8. Konstantinides SV, Meyer G, Becattini C, et al. 2019 ESC Guidelines for the diagnosis and management of acute pulmonary embolism developed in collaboration with the European Respiratory Society (ERS): The Task Force for the diagnosis and management of acute pulmonary embolism of the European Society of Cardiology (ESC). Eur Respir J. 2019; 54(3), doi: 10.1183/13993003.01647-2019, indexed in Pubmed: 31473594.

9. Moos SI, van Vemde DNH, Stoker J, et al. Contrast induced nephropathy in patients undergoing intravenous (IV) contrast enhanced computed tomography (CECT) and the relationship with risk factors: a meta-analysis. Eur J Radiol. 2013; 82(9): e387-e399, doi: 10.1016/j.ejrad.2013.04.029, indexed in Pubmed: 23711425.

10. Goldenberg I, Matetzky S. Nephropathy induced by contrast media: pathogenesis, risk factors and preventive strategies. CMAJ. 2005; 172(11): 1461-1471, doi: 10.1503/cmaj.1040847, indexed in Pubmed: 15911862.

11. Mauritz GJ, Marcus JT, Westerhof N, et al. Prolonged right ventricular post-systolic isovolumic period in pulmonary arterial hypertension is not a reflection of diastolic dysfunction. Heart. 2011; 97(6): 473-478, doi: 10.1136/hrt.2010.193375, indexed in Pubmed: 20930045.

12. Piazza G, Goldhaber SZ. The acutely decompensated right ventricle: pathways for diagnosis and management. Chest. 2005; 128(3): 1836-1852, doi: 10.1378/chest.128.3.1836, indexed in Pubmed: 16162794.

13. Harjola VP, Mebazaa A, Čelutkienė J, et al. Contemporary management of acute right ventricular failure: a statement from the Heart Failure Association and the Working Group on Pulmonary 
Circulation and Right Ventricular Function of the European Society of Cardiology. Eur J Heart Fail. 2016; 18(3): 226-241, doi: 10.1002/ejhf.478, indexed in Pubmed: 26995592.

14. Damman K, van Deursen VM, Navis G, et al. Increased central venous pressure is associated with impaired renal function and mortality in a broad spectrum of patients with cardiovascular disease. J Am Coll Cardiol. 2009; 53(7): 582-588, doi: 10.1016/j. jacc.2008.08.080, indexed in Pubmed: 19215832.

15. Burrowes KS, Clark AR, Tawhai MH. Blood flow redistribution and ventilation-perfusion mismatch during embolic pulmonary arterial occlusion. Pulm Circ. 2011; 1(3): 365-376, doi: 10.4103/2045-8932.87302, indexed in Pubmed: 22140626.

16. Pisani A, Riccio E, Andreucci M, et al. Role of reactive oxygen species in pathogenesis of radiocontrast-induced nephropathy. Biomed Res Int. 2013; 2013: 868321, doi: 10.1155/2013/868321, indexed in Pubmed: 24459673.

17. Kooiman J, Klok FA, Mos ICM, et al. Incidence and predictors of contrast-induced nephropathy following CT-angiography for clinically suspected acute pulmonary embolism. J Thromb Haemost. 2010; 8(2): 409-411, doi: 10.1111/j.1538-7836.2009.03698.x, indexed in Pubmed: 19943871.

18. Doganay S, Oguz AK, Ergun I. Increased risk of contrastinduced acute kidney injury in patients with pulmonary thromboembolism. Ren Fail. 2015; 37(7): 1138-1144, doi: 10.3109/0886022X.2015.1061869, indexed in Pubmed: 26139228.

19. Mehran R, Aymong ED, Nikolsky E, et al. A simple risk score for prediction of contrast-induced nephropathy after percutaneous coronary intervention: development and initial validation. J Am Coll Cardiol. 2004; 44(7): 1393-1399, doi: 10.1016/j. jacc.2004.06.068, indexed in Pubmed: 15464318.

20. Jiménez D, Aujesky D, Moores L, et al. RIETE Investigators. Simplification of the pulmonary embolism severity index for prognostication in patients with acute symptomatic pulmonary embolism. Arch Intern Med. 2010; 170(15): 1383-1389, doi: 10.1001/archinternmed.2010.199, indexed in Pubmed: 20696966.

21. Ho KM, Harahsheh Y. Predicting contrast-induced nephropathy after CT pulmonary angiography in the critically ill: a retrospective cohort study. J Intensive Care. 2018; 6: 3, doi: 10.1186/ s40560-018-0274-z, indexed in Pubmed: 29387419.

22. Mitchell AM, Jones AE, Tumlin JA, et al. Prospective study of the incidence of contrast-induced nephropathy among patients evaluated for pulmonary embolism by contrast-enhanced computed tomography. Acad Emerg Med. 2012; 19(6): 618-625, doi: 10.1111/j.1553-2712.2012.01374.x, indexed in Pubmed: 22687176.

23. van der Molen AJ, Reimer P, Dekkers IA, et al. Post-contrast acute kidney injury. Part 2: risk stratification, role of hydration and other prophylactic measures, patients taking metformin and chronic dialysis patients: recommendations for updated ESUR Contrast Medium Safety Committee guidelines. Eur Radiol. 2018; 28(7): 2856-2869, doi: 10.1007/s00330-017-5247-4, indexed in Pubmed: 29417249.

24. Turedi S, Erdem E, Karaca Y, et al. The high risk of contrast-induced nephropathy in patients with suspected pulmonary embolism despite three different prophylaxis: a randomized controlled trial. Acad Emerg Med. 2016; 23(10): 1136-1145, doi: 10.1111/ acem.13051, indexed in Pubmed: 27411777.

25. Kooiman J, Sijpkens YWJ, van Buren M, et al. Randomised trial of no hydration vs. sodium bicarbonate hydration in patients with chronic kidney disease undergoing acute computed tomographypulmonary angiography. J Thromb Haemost. 2014; 12(10): 1658-1666, doi: 10.1111/jth.12701, indexed in Pubmed: 25142085.

26. Timal RJ, Kooiman J, Sijpkens YWJ, et al. Effect of no prehydration vs sodium bicarbonate prehydration prior to contrast-enhanced computed tomography in the prevention of postcontrast acute kidney injury in adults with chronic kidney disease: the Kompas Randomized Clinical Trial. JAMA Intern Med. 2020; 180(4): 533-541, doi: 10.1001/jamainternmed.2019.7428, indexed in Pubmed: 32065601.
27. Goldhaber SZ, Visani L, De Rosa M. Acute pulmonary embolism: clinical outcomes in the International Cooperative Pulmonary Embolism Registry (ICOPER). Lancet. 1999; 353(9162): 1386-1389, doi: 10.1016/s0140-6736(98)07534-5, indexed in Pubmed: 10227218.

28. Zondag W, Vingerhoets LMA, Durian MF, et al. Hestia Study Investigators. Hestia criteria can safely select patients with pulmonary embolism for outpatient treatment irrespective of right ventricular function. J Thromb Haemost. 2013; 11(4): 686-692, doi: 10.1111/jth.12146, indexed in Pubmed: 23336721.

29. Pływaczewska M, Skowrońska M, Dzikowska-Diduch O, et al. Prognosis assesment in patients with acute pulmonary embolism using GFR, based on the sPESI scale and plasma troponin concentration. The 4 th International Spring School The science and practice of VTE. Abstract Book. 2019; May: 36-37.

30. Catella J, Bertoletti L, Mismetti P, et al. investigators of the RIETE registry. Severe renal impairment and risk of bleeding during anticoagulation for venous thromboembolism. J Thromb Haemost. 2020; 18(7): 1728-1737, doi: 10.1111/jth.14837, indexed in Pubmed: 32299150.

31. Altınsoy B, Öz İ̈, Örnek T, et al. Prognostic value of renal dysfunction indicators in normotensive patients with acute pulmonary embolism. Clin Appl Thromb Hemost. 2017; 23(6): 554-561, doi: 10.1177/1076029616637440, indexed in Pubmed: 27013086 .

32. KDIGO 2012: Clinical practice guideline for the evaluation and management of chronic kidney disease. Kidney International Supplements. 2013; 3(1): 134-135, doi: 10.1038/kisup.2012.71.

33. Kjeldsen L, Cowland J, Borregaard N. Human neutrophil gelatinase-associated lipocalin and homologous proteins in rat and mouse. Biochim Biophys Acta. 2000; 1482(1-2): 272-283, doi: 10.1016/s0167-4838(00)00152-7.

34. Coca SG, Yalavarthy R, Concato J, et al. Biomarkers for the diagnosis and risk stratification of acute kidney injury: a systematic review. Kidney Int. 2008; 73(9): 1008-1016, doi: 10.1038/ sj.ki.5002729, indexed in Pubmed: 18094679.

35. Kostrubiec M, Łabyk A, Pedowska-Włoszek J, et al. Neutrophil gelatinase-associated lipocalin, cystatin $\mathrm{C}$ and eGFR indicate acute kidney injury and predict prognosis of patients with acute pulmonary embolism. Heart. 2012; 98(16): 1221-1228, doi: 10.1136/heartjnl-2012-301884, indexed in Pubmed: 22705926.

36. Galiè N, Humbert M, Vachiery JL, et al. 2015 ESC/ERS Guidelines for the diagnosis and treatment of pulmonary hypertension. The Joint Task Force for the Diagnosis and Treatment of Pulmonary Hypertension of the European Society of Cardiology (ESC) and the European Respiratory Society (ERS): Endorsed by: Association for European Paediatric and Congenital Cardiology (AEPC), International Society for Heart and Lung Transplantation (ISHLT). Eur Respir J. 2015; 46: 903-975, doi: 10.1183/13993003.01032-2015.

37. Ende-Verhaar YM, Cannegieter SC, Vonk Noordegraaf A, et al. Incidence of chronic thromboembolic pulmonary hypertension after acute pulmonary embolism: a contemporary view of the published literature. Eur Respir J. 2017; 49(2), doi: 10.1183/13993003.01792-2016, indexed in Pubmed: 28232411.

38. Lang IM, Madani M. Update on chronic thromboembolic pulmonary hypertension. Circulation. 2014; 130(6): 508-518, doi: 10.1161/ CIRCULATIONAHA.114.009309, indexed in Pubmed: 25092279.

39. Gajanana D, Mezue K, George J, et al. Effects of pulmonary hypertension on kidney function. Clin Pulm Med. 2017; 24(1) 26-28, doi: 10.1097/cpm.0000000000000184.

40. Mullens W, Abrahams Z, Francis GS, et al. Importance of venous congestion for worsening of renal function in advanced decompensated heart failure. J Am Coll Cardiol. 2009; 53(7): 589-596, doi: 10.1016/j.jacc.2008.05.068, indexed in Pubmed: 19215833.

41. Sarnak MJ. A patient with heart failure and worsening kidney function. Clin J Am Soc Nephrol. 2014; 9(10): 1790-1798, doi: 10.2215/CJN.11601113, indexed in Pubmed: 24763864. 
42. Heymes C, Bendall JK, Ratajczak P, et al. Increased myocardial NADPH oxidase activity in human heart failure. J Am Coll Cardiol. 2003; 41(12): 2164-2171, doi: 10.1016/s0735-1097(03)00471-6, indexed in Pubmed: 12821241.

43. Nickel NP, O'Leary JM, Brittain EL, et al. Kidney dysfunction in patients with pulmonary arterial hypertension. Pulm Circ. 2017; 7(1): 38-54, doi: 10.1086/690018, indexed in Pubmed: 28680564.

44. Nootens M, Kaufmann E, Rector T, et al. Neurohormonal activation in patients with right ventricular failure from pulmonary hypertension: Relation to hemodynamic variables and endothelin levels. J Am Coll Cardiol. 1995; 26(7): 1581-1585, doi: 10.1016/0735-1097(95)00399-1.

45. de Man FS, Tu Ly, Handoko ML, et al. Dysregulated renin-angiotensin-aldosterone system contributes to pulmonary arterial hypertension. Am J Respir Crit Care Med. 2012; 186(8): 780789, doi: 10.1164/rccm.201203-04110C, indexed in Pubmed: 22859525 .

46. Sise ME, Courtwright AM, Channick RN. Pulmonary hypertension in patients with chronic and end-stage kidney disease. Kidney Int. 2013; 84(4): 682-692, doi: 10.1038/ki.2013.186, indexed in Pubmed: 23739239.

47. Navaneethan SD, Roy J, Tao K, et al. Prevalence, Predictors, and Outcomes of Pulmonary Hypertension in CKD. J Am Soc Nephrol. 2016; 27(3): 877-886, doi: 10.1681/ASN.2014111111, indexed in Pubmed: 26386072.

48. Riedel M, Stanek V, Widimsky J, et al. Longterm follow-up of patients with pulmonary thromboembolism. Late prognosis and evolution of hemodynamic and respiratory data. Chest. 1982; 81(2): 151-158, doi: 10.1378/chest.81.2.151, indexed in Pubmed: 7056079.

49. Mayer E, Jenkins D, Lindner J, et al. Surgical management and outcome of patients with chronic thromboembolic pulmonary hypertension: results from an international prospective registry. J Thorac Cardiovasc Surg. 2011; 141(3): 702-710, doi: 10.1016/j. jtcvs.2010.11.024, indexed in Pubmed: 21335128.

50. Madani MM, Auger WR, Pretorius V, et al. Pulmonary endarterectomy: recent changes in a single institution's experience of more than 2,700 patients. Ann Thorac Surg. 2012; 94(1): 97-103; discussion 103, doi: 10.1016/j.athoracsur.2012.04.004, indexed in Pubmed: 22626752

51. Delcroix M, Lang I, Pepke-Zaba J, et al. Long-Term outcome of patients with chronic thromboembolic pulmonary hypertension: results from an international prospective registry. Circulation. 2016; 133(9): 859-871, doi: 10.1161/CIRCULATIONAHA.115.016522, indexed in Pubmed: 26826181.

52. Mahmud E, Madani MM, Kim NH, et al. Chronic thromboembolic pulmonary hypertension: evolving therapeutic approaches for operable and inoperable disease. J Am Coll Cardiol. 2018; 71(21): 2468-2486, doi: 10.1016/j.jacc.2018.04.009, indexed in Pubmed: 29793636.

53. Freed DH, Thomson BM, Berman M, et al. Survival after pulmonary thromboendarterectomy: effect of residual pulmonary hypertension. J Thorac Cardiovasc Surg. 2011; 141(2): 383-387, doi: 10.1016/j.jtcvs.2009.12.056, indexed in Pubmed: 20471039.

54. Wilkens H, Konstantinides S, Lang IM, et al. Chronic thromboembolic pulmonary hypertension (CTEPH): Updated Recommendations from the Cologne Consensus Conference 2018. Int J Cardiol. 2018; 272S: 69-78, doi: 10.1016/j.ijcard.2018.08.079, indexed in Pubmed: 30195840.
55. Mizoguchi H, Ogawa A, Munemasa M, et al. Refined balloon pulmonary angioplasty for inoperable patients with chronic thromboembolic pulmonary hypertension. Circ Cardiovasc Interv. 2012; 5(6): 748-755, doi: 10.1161/CIRCINTERVENTIONS.112.971077, indexed in Pubmed: 23192917.

56. Roik M, Wretowski D, Łabyk A, et al. Refined balloon pulmonary angioplasty-A therapeutic option in very elderly patients with chronic thromboembolic pulmonary hypertension. J Interv Cardiol. 2017; 30(3): 249-255, doi: 10.1111/joic.12387, indexed in Pubmed: 28474349.

57. Zoppellaro G, Badawy MR, Squizzato A, et al. Balloon pulmonary angioplasty in patients with chronic thromboembolic pulmonary hypertension: a systematic review and meta-analysis. Circ J. 2019; 83(8): 1660-1667, doi: 10.1253/circj.CJ-19-0161, indexed in Pubmed: 31231116.

58. Darocha S, Banaszkiewicz M, Pietrasik A, et al. Changes in estimated glomerular filtration after balloon pulmonary angioplasty for chronic thromboembolic pulmonary hypertension. Cardiorenal Med. 2020; 10(1): 22-31, doi: 10.1159/000502254, indexed in Pubmed: 31527376.

59. Marenzi G, Cosentino N, Bartorelli AL. Acute kidney injury in patients with acute coronary syndromes. Heart. 2015; 101(22): 1778-1785, doi: 10.1136/heartjnl-2015-307773, indexed in Pubmed: 26243789 .

60. Kriechbaum SD, Wiedenroth CB, Hesse ML, et al. Development of renal function during staged balloon pulmonary angioplasty for inoperable chronic thromboembolic pulmonary hypertension. Scand J Clin Lab Invest. 2019; 79(4): 268-275, doi: 10.1080/00365513.2019.1601765, indexed in Pubmed: 30987470.

61. Kimura M, Kataoka M, Kawakami T, et al. Balloon pulmonary angioplasty using contrast agents improves impaired renal function in patients with chronic thromboembolic pulmonary hypertension. Int J Cardiol. 2015; 188: 41-42, doi: 10.1016/j. ijcard.2015.04.030, indexed in Pubmed: 25880583.

62. Isobe $\mathrm{S}$, Itabashi $\mathrm{Y}$, Kawakami T, et al. Increasing mixed venous oxygen saturation is a predictor of improved renal function after balloon pulmonary angioplasty in patients with chronic thromboembolic pulmonary hypertension. Heart Vessels. 2019; 34(4): 688-697, doi: 10.1007/s00380-018-1284-4, indexed in Pubmed: 30386916.

63. Naranjo M, Lo KB, Mezue K, et al. Effects of pulmonary hypertension and right ventricular function in short and long-term kidney function. Curr Cardiol Rev. 2019; 15(1): 3-11, doi: 10.217 4/1573403X14666181008154215, indexed in Pubmed: 30306876.

64. Navaneethan SD, Roy J, Tao K, et al. Prevalence, predictors, and outcomes of pulmonary hypertension in CKD. J Am Soc Nephrol. 2016; 27(3): 877-886, doi: 10.1681/ASN.2014111111, indexed in Pubmed: 26386072.

65. Chakinala MM, Coyne DW, Benza RL, et al. Predicting outcomes in pulmonary arterial hypertension based on estimated glomerular filtration rate. Am J Respir Crit Care Med. 2016; 193: A6316.

66. Bolignano D, Rastelli S, Agarwal R, et al. Pulmonary hypertension in CKD. Am J Kidney Dis. 2013; 61(4): 612-622, doi: 10.1053/j.ajkd.2012.07.029, indexed in Pubmed: 23164943.

67. Simonneau G, Montani D, Celermajer D, et al. Haemodynamic definitions and updated clinical classification of pulmonary hypertension. Eur Respir J. 2019; 53(1): 1801913, doi: 10.1183/13993003.01913-2018. 